\title{
RELATIVISTIC ENERGY APPROACH AND MANY-BODY PERTURBATION THEORY TO COMPUTING ELECTRON-COLLISION CROSS-SECTIONS OF COMPLEX MULTIELECTRON IONS
}

\begin{abstract}
An advanced relativistic energy approach combined with a relativistic many-body perturbation theory with ab initio zeroth approximation is used to calculate the electron-collision excitation cross-sections for complex multielectron systems. The relativistic many-body perturbation theory is used alongside the gauge-invariant scheme to generate an optimal Dirac-Kohn-Sham- Debye-Hückel one-electron representation. The results of relativistic calculation (taking into account the exchange and correlation corrections) of the electron collision cross-sections of excitation for the neon-like ion of the krypton are presented and compared with alternative results calculation on the basis of the R-matrix method in the Breit-Pauli approximation, in the relativistic distorted wave approximation and R- matrix method in combination with Dirac-Fock approximation.
\end{abstract}

\section{Introduction}

Electron-collisional spectroscopy of atoms and multicharged ions is one of the most fast developing branches of modern atomic spectroscopy. The properties of laboratory and astrophysical plasmas have drawn considerable attention over the last decades [1-50]. It is known that multicharged ions play an important role in the diagnostics of a wide variety of plasmas. Similar interest is also stimulated by importance of this information for correct determination of the characteristics for plasma in thermonuclear (tokamak) reactors, searching new mediums for X-ray range lasers.

In the last years an especial interest attracts study of multicharged ions of isoelectronic sequences of the inert atoms (neon, krypton, argon). The sought objects of research, firstly, belong to the class of complex relativistic many-electron atomic systems, in connection with which the approbation of the theory is extremely important and indicative just for such systems. Second, the sought multiply charged ions are of great interest for a number of applications in the field of laser physics and quantum electronics, in particular, the use of the plasma of the corresponding ions as an active medium for short-wavelength lasers, further in the field of diagnostics of astrophysical, laboratory and fusion reactor plasma, tokamak and EBIT devices, as well as, of course, laser plasma

In the case of solving collision problems involving multi-electron atomic systems, as well as low-energy processes, etc., the structure of atomic systems should be described on the basis of rigorous methods of quantum theory. As a rule, the Hartree-Fock (HF) or Hartree-Fock-Slater (HFS) models implemented in the tight-binding approximation were used to describe the wave functions of the bound states of atoms and ions. Another direction is the models of the central potential (model potential, pseudopotential) implemented in the distorted wave approximation (DWA). It should be mentioned the currently widespread and widely used R-matrix method and its various promising modifications, as well as a generalization of the wellknown Dirac-Fock method to the case of taking into account multipolarity in the corresponding operators (see, e.g. , [1-7]). It should be noted that, depending on the perturbation theory (PT) basis used, different versions of the R-matrix method received the corresponding names. For example, in specific calculations such versions as R-MATRCI3-5R and R-MATR-41 R-matrix method were used using respectively wave functions in the multiconfiguration approximation, in particular, 5- and 41- configuration wave 
functions. As numerous applications of the R-matrix method have shown, it has certain advantages in terms of accuracy and consistency over such popular approaches as the first-order PT method, as well as the distorted wave approximation taking into account configuration interaction ( CI-DWBA); --approximation of distorted waves using the HF basis (HF-DWBA), finally, the relativistic approximation of distorted waves with a 1-configuration and multi-configuration wave function of the ground state (SCGSRDWA, MCGS-RDWA, etc.). Improved models have also appeared in theories of the coupled-channel (VC) type VCDWA (Variational Continuum Distorted Wave), for example, a modification of the Vraun-Scroters type and others (see [1-5]). Various cluster methods have also been widely used (see in more details $[1-3,14,15])$.

In this paper, we present and use an advanced relativistic energy approach to calculate the electron-ion collision strengths, effective collision strengths and the associated cross sections. The relativistic many-body PT is utilised alongside the gauge-invariant scheme to generate an optimal one-electron representation. The calculated effective collision strengths of the Ne-like krypton excitation are listed.

\section{Advanced energy approach to elec- tron collision strengths for atomic systems}

The detailed description of our approach was earlier presented (see, for example, Refs. [7-9,13]). Therefore, below we are limited only by the key points. The generalized relativistic energy approach combined with the RMBPT has been in details described in Refs. [6,14-18]. It generalizes earlier developed energy approach $[6,16]$.

The key idea is in calculating the energy shifts $\Delta E$ of degenerate states that is connected with the secular matrix $M$ diagonalization $[6,16]$. To construct $M$, one should use the Gell-Mann and Low adiabatic formula for $\Delta E$. The secular matrix elements are already complex in the PT second order. The whole calculation is reduced to calculation and diagonalization of the complex matrix $M$.and definition of matrix of the coefficients with eigen state vectors $B_{i e, i v}^{I K}[6,8,9]$.

To calculate all necessary matrix elements one must use the basis's of the 1QP relativistic functions. Within an energy approach the total energy shift of the state is usually presented as $[6,16]$ :

$$
\Delta \mathrm{E}=\operatorname{Re} \Delta \mathrm{E}+\mathrm{i} \Gamma / 2
$$

where $\Gamma$ is interpreted as the level width and decay possibility $P=\Gamma$. The imaginary part of electron energy of the system, which is defined in the lowest PT order as [6]:

$$
\operatorname{Im} \Delta E(B)=-\frac{e^{2}}{4 \pi} \underset{\substack{\alpha>n>f \\ \alpha<<n \leq f]}}{\sum_{\alpha n \alpha n}\left|\omega_{\alpha n}\right|}
$$

where $\sum_{\alpha>n>f}$ for electron and $\sum_{\alpha<n \leq f}$ for vacancy.

The separated terms of the sum in (3) represent the contributions of different channels. It is known that their adequate description requires using the optimized basis's of wave functions. In [6] it has been proposed "ab initio" optimization principle for construction of cited basis's. It uses a minimization of the gauge dependent multielectron contribution of the lowest QED PT corrections to the radiation widths of atomic levels. This contribution describes collective effects and it is dependent upon the electromagnetic potentials gauge (the gauge non-invariant contribution $\left.\delta \mathrm{E}_{\text {ninv }}\right)$. The minimization of $\operatorname{Im} \delta \mathrm{E}_{\text {ninv }}$ leads to integral differential equation, that is numerically solved. In result one can get the optimal one-electron basis of the PT $[14,16,17]$. It is worth to note that this approach was used under solving of multiple problems of modern atomic, nuclear and molecular physics (see [14-25]). The scattered part of $\operatorname{Im} \Delta E$ appears first in the second order of the atomic PT. The collisional deexcitation cross section is defined as follows $[6,8,9]$ :

$$
\sigma(I K \rightarrow 0)=2 \pi \sum_{j_{i n}, j_{s c}}\left(2 j_{s c}+1\right) *
$$




$$
\begin{gathered}
*\left\{\sum_{j_{i e, ~}, j_{i v}}<0\left|j_{i n}, j_{s c}\right| j_{i e}, j_{i v}, J_{i}>B_{i e, i v}^{I K}\right\}^{2}, \\
<0\left|j_{i n}, j_{s c}\right| j_{i e}, j_{i v}, J_{i}>= \\
\sqrt{\left(2 j_{i e}+1\right)\left(2 j_{i v}+1\right)}(-1)^{j_{i e}+1 / 2} \times \sum_{\lambda}(-1)^{\lambda+J_{i}} \times \\
\times\left\{\delta_{\lambda, J_{i}} /\left(2 J_{i}+1\right) Q_{\lambda}(s c, i e ; i v, i n)+\right. \\
\left.\left[\begin{array}{l}
j_{i n} \ldots j_{s c} \ldots J_{i} \\
j_{i e} \ldots j_{i v} \ldots . . \lambda
\end{array}\right] Q_{\lambda}(i e ; i n ; i v, s c)\right\}
\end{gathered}
$$

where $Q_{\lambda}$ is the sum of the known Coulomb and Breit matrix elements $[6,14,16]$. The effective collision strength $\Omega(I \rightarrow F)$ is associated with a collisional cross section $\sigma$ as follows (in the Coulomb units):

$$
\begin{aligned}
& \sigma(I \rightarrow F)=\Omega(I \rightarrow F) \cdot \pi / \\
& /\left\{\left(2 J_{i}+1\right) \varepsilon_{i n}\left[(\alpha Z)^{2} \varepsilon_{i n}+2\right]\right\}
\end{aligned}
$$

where $Z$ is the nucleus charge and $\alpha$ is the fine structure constant, $\varepsilon_{i n}$ is the incident energy. Further let us firstly consider the Debye shielding model according to Refs. [7-9]. It is known in the classical theory of plasmas developed by Debye-Hückel, the interaction potential between two charged particles is modelled by the Yukawa-type potential, which contains the shielding parameter $\mu$. The parameter $\mu$ is connected with the plasma parameters such as the temperature $T$ and the charge density $\mathrm{n}$ as follows: $\mu \sim \sqrt{e^{2} n / k_{B} T}$. Here, as usually, $\mathrm{e}$ is the electron charge and $\kappa_{b}$ is the Boltzman constant.

It should be noted that indeed the Debye screening for the atomic electrons in the Coulomb field of nuclear charge is well understood due to the presence of the surrounding plasma electrons with high mobility. On the other hand, the contribution due to the Debye screening between electrons would be of smaller magnitude orders.
Majority of the previous works on the spectroscopy study have considered the screening effect only in the electron-nucleus potential where the electron-electron interaction potential is truncated at its first term of the standard exponential expansion for its dominant contribution [3-69]. However, it is also important to take into account the screening in the electron- electron interactions for large plasma strengths to achieve more realistic results in the search for stability of the atomic structure in the plasma environment.

By introducing the Yukawa-type e-N and e-e interaction potentials, an electronic Hamiltonian for $\mathrm{N}$-electron ion in a plasma is in atomic units as follows [7]:

$$
\begin{gathered}
H=\sum_{i}\left[\alpha c p-\beta m c^{2}-Z \exp \left(-\mu r_{i}\right) / r_{i}\right]+ \\
+\sum_{i>j} \frac{\left(1-\alpha_{i} \alpha_{j}\right)}{r_{i j}} \exp \left(-\mu r_{i j}\right)
\end{gathered}
$$

To generate the wave functions basis we use the optimized Dirac-Kohn-Sham potential with one parameter $[14,15]$, which calibrated within the special ab initio procedure within the relativistic energy approach [16,17]. More details, including the procedures of computing amplitudes, radial intagrals, matrix elements etc, can be found in Refs. [723]. All calculations are performed on the basis of the code Superatom-ISAN (version 93).

\section{Results and conclusion}

Table 1 shows the values of the cross sections for the excitation of some states of the $\mathrm{Kr}^{26+}$ multicharged ion from the ground state (the energy of the incident electron are $4.082 \mathrm{keV}$ ) obtained within the framework of the relativistic many-body perturbation theory and relativistic energy formalism [7-23].

In Table 1 there are also listed the data (for the first 26 excited states) of the calculation by the R-matrix method in the Breit-Pauli approximation by Gupta et al (BP-RM), in the relativistic distorted wave approximation 
(RDWA), R- matrix method in the DF approximation by Griffin et al (MCDF-RM) (e.g. [2] and Refs. therein).

Table 1.

Cross sections for excitation by electron impact of the $\mathrm{Kr}^{26+}$ excited states at the incident electron energy of $4.082 \mathrm{keV}$

\begin{tabular}{|c|c|c|}
\hline Level & BP-R-M & RDWA \\
\hline $2 p^{5} 3 \mathrm{~s}(3 / 2,1 / 2)_{2}$ & $8.94(-23)$ & $8.80(-23)$ \\
\hline $2 \mathrm{p}^{5} 3 \mathrm{~s}(3 / 2,1 / 2)_{1}$ & $5.22(-22)$ & $6.63(-22)$ \\
\hline $2 p^{5} 3 p(3 / 2,1 / 2)_{1}$ & $1.60(-22)$ & $1.73(-22)$ \\
\hline $2 p^{5} 3 p(3 / 2,1 / 2)_{2}$ & $4.25(-22)$ & $4.72(-22)$ \\
\hline $2 \mathrm{p}^{5} 3 \mathrm{~s}(1 / 2,1 / 2)_{0}$ & $1.90(-23)$ & $1.76(-23)$ \\
\hline $2 \mathrm{p}^{5} 3 \mathrm{~s}(1 / 2,1 / 2)_{1}$ & $2.99(-22)$ & $4.16(-22)$ \\
\hline $2 p^{5} 3 p(3 / 2,3 / 2)_{3}$ & $2.30(-22)$ & $2.20(-22)$ \\
\hline $2 p^{5} 3 p(3 / 2,3 / 2)_{1}$ & $1.10(-22)$ & $1.06(-22)$ \\
\hline $2 p^{5} 3 p(3 / 2,3 / 2)_{2}$ & $3.81(-22)$ & $3.90(-22)$ \\
\hline $2 p^{5} 3 p(3 / 2,3 / 2)_{0}$ & $2.06(-21)$ & 2.05( \\
\hline $2 p^{5} 3 p(1 / 2,1 / 2)_{1}$ & $9.44(-23)$ & $9.09(-23)$ \\
\hline $2 p^{5} 3 p(1 / 2,3 / 2)_{1}$ & $1.11(-22)$ & $1.11(-22)$ \\
\hline $2 p^{5} 3 p(1 / 2,3 / 2)_{2}$ & $3.81(-22)$ & $4.31(-22)$ \\
\hline $2 p^{5} 3 d(3 / 2,3 / 2)_{0}$ & $9.85(-23)$ & $9.97(-23)$ \\
\hline $2 p^{5} 3 p(1 / 2.1 / 2)_{0}$ & $5.48(-21)$ & $5.40(-21)$ \\
\hline $2 \mathrm{p}^{5} 3 \mathrm{~d}(3 / 2,3 / 2)_{1}$ & $3.08(-22)$ & $3.11(-22)$ \\
\hline $2 \mathrm{p}^{5} 3 \mathrm{~d}(3 / 2,3 / 2)_{3}$ & $4.75(-22)$ & 4.66( \\
\hline $2 \mathrm{p}^{5} 3 \mathrm{~d}(3 / 2,5 / 2)_{2}$ & $2.92(-22)$ & $2.90(-22)$ \\
\hline $2 \mathrm{p}^{5} 3 \mathrm{~d}(3 / 2,5 / 2)_{4}$ & $3.11(-22)$ & 2.99( \\
\hline $2 \mathrm{p}^{5} 3 \mathrm{~d}(3 / 2,3 / 2)_{2}$ & $1.33(-22)$ & $1.26(-22)$ \\
\hline $2 \mathrm{p}^{5} 3 \mathrm{~d}(3 / 2.5 / 2)_{3}$ & $3.67(-22)$ & $3.61(-22)$ \\
\hline $2 p^{5} 3 d(3 / 2,5 / 2)_{1}$ & $1.30(-20)$ & $1.46(-20)$ \\
\hline $2 p^{5} 3 d(1 / 2,3 / 2)_{2}$ & $1.55(-22)$ & $1.47(-22)$ \\
\hline $2 \mathrm{p}^{5} 3 \mathrm{~d}(1 / 2,5 / 2)_{2}$ & $2.44(-22)$ & $2.32(-22)$ \\
\hline $2 \mathrm{p}^{5} 3 \mathrm{~d}(1 / 2,5 / 2)_{3}$ & $4.40(-22)$ & $4.25(-22)$ \\
\hline $2 \mathrm{p}^{5} 3 \mathrm{~d}(1 / 2,3 / 2)_{2}$ & $1.64(-20)$ & $1.46(-20)$ \\
\hline Level & DF-RM & Our data \\
\hline $2 p^{5} 3 \mathrm{~s}(3 / 2,1 / 2)_{2}$ & $9.98(-23)$ & $9.75(-23)$ \\
\hline $2 \mathrm{p}^{5} 3 \mathrm{~s}(3 / 2,1 / 2)_{1}$ & $7.29(-22)$ & $7.05(-22)$ \\
\hline $2 p^{5} 3 p(3 / 2,1 / 2)_{1}$ & $1.85(-22)$ & $1.80(-22)$ \\
\hline $2 p^{5} 3 p(3 / 2,1 / 2)_{2}$ & $4.88(-22)$ & $4.81(-22)$ \\
\hline $2 p^{5} 3 s(1 / 2,1 / 2)_{0}$ & $2.01(-23)$ & $1.97(-23)$ \\
\hline $2 \mathrm{p}^{5} 3 \mathrm{~s}(1 / 2,1 / 2)_{1}$ & $4.52(-22)$ & $4.38(-22)$ \\
\hline $2 p^{5} 3 p(3 / 2,3 / 2)_{3}$ & $2.34(-22)$ & $2.32(-22)$ \\
\hline $2 p^{5} 3 p(3 / 2,3 / 2)_{1}$ & $1.20(-22)$ & $1.17(-22)$ \\
\hline $2 p^{5} 3 p(3 / 2,3 / 2)_{2}$ & $4.17(-22)$ & $4.13(-22)$ \\
\hline $2 p^{5} 3 p(3 / 2,3 / 2)_{0}$ & $2.02(-21)$ & $1.98(-21)$ \\
\hline
\end{tabular}

\begin{tabular}{|c|c|}
\hline $2 p^{5} 3 p(1 / 2,1 / 2)_{1}$ & $1.01(-22) 9.98(-23)$ \\
\hline $2 p^{5} 3 p(1 / 2,3 / 2)_{1}$ & $1.21(-22) 1.18$ \\
\hline $2 p^{5} 3 p(1 / 2,3 / 2)_{2}$ & $4.41(-22) 4.37(-22)$ \\
\hline $2 \mathrm{p}^{5} 3 \mathrm{~d}(3 / 2,3 / 2)_{0}$ & $1.04(-22) 1.01(-22)$ \\
\hline $2 p^{5} 3 p(1 / 2.1 / 2)_{0}$ & $5.08(-21) 5.03(-21)$ \\
\hline $2 p^{5} 3 d(3 / 2,3 / 2)_{1}$ & $3.34(-22) 3.30(-22)$ \\
\hline $2 p^{5} 3 d(3 / 2,3 / 2)_{3}$ & $4.78(-22) 4.71(-22)$ \\
\hline $2 p^{5} 3 d(3 / 2,5 / 2)_{2}$ & $3.00(-22) 2.98(-22)$ \\
\hline $2 p^{5} 3 d(3 / 2,5 / 2)_{4}$ & $3.17(-22) 3.14(-22)$ \\
\hline $2 p^{5} 3 d(3 / 2,3 / 2)_{2}$ & $1.42(-22) 1.39(-22)$ \\
\hline $2 p^{5} 3 d(3 / 2.5 / 2)_{3}$ & $3.62(-22) 3.60(-22)$ \\
\hline $2 p^{5} 3 d(3 / 2,5 / 2)_{1}$ & $1.45(-20) 1.42(-20)$ \\
\hline $2 p^{5} 3 d(1 / 2,3 / 2)_{2}$ & $1.58(-22) 1.57(-22)$ \\
\hline $2 p^{5} 3 d(1 / 2,5 / 2)_{2}$ & $2.44(-22) 2.42(-22)$ \\
\hline $2 \mathrm{p}^{5} 3 \mathrm{~d}(1 / 2,5 / 2)_{3}$ & $4.31(-22) 4.29(-22)$ \\
\hline $2 p^{5} 3 d(1 / 2,3 / 2)_{2}$ & $1.72(-20) 1.69(-20)$ \\
\hline
\end{tabular}

Analyzing the presented data, it should be noted that shortened bases are used in the BP-RM methods and the relativistic distorted wave approximation by Reed et al (RDWA), as a result of which, as noted also by Griffin et al [20], the data on the cross sections of state excitation the krypton ion are strongly underestimated.

\section{References}

1. Badnell, N.R. Calculations for electron-ion collisions and photoionization processes for plasma modeling. $J$. Phys.: Conf. Ser. 2007, 88, 012070.

2. Griffin, D.C., Balance, C., Mitnik, D., Berengut, J.C. Dirac $R$-matrix calculations of electron-impact excitation of neon-like krypton. J. Phys. B: At. Mol. Opt. Phys. 2008, 41, 215201.

3. Yongqiang, Li; Jianhua, Wu; Yong, Hou, Jianmin Yuan. Influence of hot and dense plasmas on energy levels and oscillator strengths of ions: Be-like ions for $Z=26-36$, J. Phys. B: At. Mol. Opt. Phys. 2008, 41, 145002.

4. Bannister, M. E., Djurić , N., Woitke, O., Dunn, G., Chung, Y. -S, Smith, A. C. H., Wallbank, B., Berrington, K. A. Absolute cross-sections for nearthreshold electron-impact excitation of 
Be-like $\mathrm{C}^{2+}, \mathrm{N}^{3+}, \mathrm{O}^{4+}$. Int. J. Mass Spectr. 1999, 192, 39-48.

5. Smith, A. C. H., Bannister, M. E., Chung, Y. -S, Djuri,ć N., Dunn, G. H., Wallbank, B., Woitke, O. Nearthreshold Electron-impact Excitation of Multiply-charged Be-like Ions. Phys.Scr. 1999, T80, 283-287.

6. Ivanov, L.N.; Ivanova, E.P.; Knight, L. Energy approach to consistent QED theory for calculation of electroncollision strengths: Ne-like ions. Phys. Rev. A. 1993, 48, 4365-4374.

7. Buyadzhi, V.V. Laser multiphoton spectroscopy of atom embedded in Debye plasmas: multiphoton resonances and transitions. Photoelectronics. 2015, 24, 128-133.

8. Buyadzhi, V.V.; Chernyakova, Yu.G.; Smirnov, A.V.; Tkach, T.B. Electroncollisional spectroscopy of atoms and ions in plasma: Be-like ions. Photoelectronics. 2016, 25, 97-101.

9. Buyadzhi, V.; Chernyakova, Yu.; Antoshkina, O.; Tkach, T. Spectroscopy of multicharged ions in plasmas: Oscillator strengths of Be-like ion Fe. Photoelectronics. 2017, 26, 94-102.

10. Glushkov, A.V.; Malinovskaya, S.V.; Prepelitsa, G.P.; Ignatenko, V. Manifestation of the new laser-electron nuclear spectral effects in the thermalized plasma: QED theory of co-operative laser-electron-nuclear processes. $J$. Phys.: Conf. Ser. 2005, 11, 199-206.

11. Glushkov, A.V.; Malinovskaya, S.V.; Chernyakova Y.G.; Svinarenko, A.A. Cooperative laser-electron-nuclear processes: QED calculation of electron satellites spectra for multi-charged ion in laser field. Int. Journ. Quant. Chem. 2004, 99, 889-893.

12. Glushkov, A.V.; Malinovskaya, S.V.; Loboda, A.V.; Shpinareva, I.M.; Gurnitskaya, E.P.; Korchevsky, D.A. Diagnostics of the collisionally pumped plasma and search of the optimal plasma parameters of $x$-ray lasing: calculation of electron-collision strengths and rate coefficients for Ne-like plasma. $J$.
Phys.: Conf. Ser. 2005, 11, 188-198.

13. Glushkov, A.V.; Ambrosov, S.V.; Loboda, A.V.; Gurnitskaya, E.P.; Prepelitsa, G.P. Consistent QED approach to calculation of electron-collision excitation cross sections and strengths: Ne-like ions. Int. J. Quantum Chem. 2005, 104, 562-569.

14. Glushkov, A.V. Relativistic Quantum theory. Quantum mechanics of atomic systems; Astroprint: Odessa, 2008.

15. Khetselius, O.Yu. Hyperfine structure of atomic spectra. Astroprint: Odessa, 2008.

16. Glushkov, A.V.; Ivanov, L.N.; Ivanova, E.P. Autoionization Phenomena in Atoms. Moscow Univ. Press, 1986, 58160

17. Glushkov, A.; Ivanov, L. Radiation decay of atomic states: atomic residue polarization and gauge noninvariant contributions. Phys. Lett. A 1992, 170, 33.

18. Glushkov, A.V. Spectroscopy of atom and nucleus in a strong laser field: Stark effect and multiphoton resonances. J. Phys.: Conf. Ser. 2014, 548, 012020

19. Ivanov, L.N.; Ivanova, E.P. Method of Sturm orbitals in calculation of physical characteristics of radiation from atoms and ions. JETP. 1996, 83, 258266.

20. Glushkov, A.V., Ivanov, L.N., Ivanova, E.P. Autoionization Phenomena in Atoms. Moscow Univ. Press, Moscow, 1986, 58.

21. Glushkov, A.V., Ivanov, L.N. Radiation decay of atomic states: atomic residue polarization and gauge noninvariant contributions. Phys. Lett. A 1992, 170, 33.

22. Glushkov, A.V.; Ivanov, L.N. DC strong-field Stark effect: consistent quantum-mechanical approach. J. Phys. B: At. Mol. Opt. Phys. 1993, 26, L379386.

23. Ivanova, E., Glushkov, A. Theoretical investigation of spectra of multicharged ions of F-like and Ne-like isoelectronic 
sequences. J. Quant. Spectr. and Rad. Tr. 1986, 36(2), 127-145.

24. Ivanova, E.P., Ivanov, L.N., Glushkov, A., Kramida, A. High order corrections in the relativistic perturbation theory with the model zeroth approximation, Mg-Like and Ne-Like Ions. Phys. Scripta 1985, 32, 513-522.

25. Glushkov, A.V. Relativistic and correlation effects in spectra of atomic systems. Astroprint: Odessa, 2006.

26. Glushkov, A.V. Multiphoton spectroscopy of atoms and nuclei in a laser field: Relativistic energy approach and radiation atomic lines moments method. Adv. in Quantum Chem. 2019, 78, 253-285.

27. Glushkov, A., Loboda, A., Gurnitskaya, E., Svinarenko, A. QED theory of radiation emission and absorption lines for atoms in a strong laser field. Phys. Scripta. 2009, T135, 014022.

28. Glushkov, A. Spectroscopy of cooperative muon-gamma-nuclear processes: Energy and spectral parameters $J$. Phys.: Conf. Ser. 2012, 397, 012011.

29. Glushkov, A.V. Spectroscopy of atom and nucleus in a strong laser field: Stark effect and multiphoton resonances. J. Phys.: Conf. Ser. 2014, 548, 012020.

30. Glushkov, A.V., Ternovsky, V.B., Buyadzhi, V., Prepelitsa, G.P. Geometry of a Relativistic Quantum Chaos: New approach to dynamics of quantum systems in electromagnetic field and uniformity and charm of a chaos. Proc. Int. Geom. Center. 2014, 7(4), 60-71.

31. Glushkov, A., Buyadzhi, V., Kvasikova, A., Ignatenko, A., Kuznetsova, A., Prepelitsa, G., Ternovsky, V. NonLinear chaotic dynamics of quantum systems: Molecules in an electromagnetic field and laser systems. In: Quantum Systems in Physics, Chemistry, and Biology. Springer, Cham. 2017, 30, 169-180.

32. Glushkov, A.V. Relativistic polarization potential of a many-electron atom.
Sov. Phys. Journal. 1990, 33(1), 1-4.

33. Glushkov, A., Svinarenko, A., Ignatenko, A. Spectroscopy of autoionization resonances in spectra of the lanthanides atoms. Photoelectronics. 2011, 20, 90-94.

34. Glushkov, A., Gurskaya, M., Ignatenko, A., Smirnov, A., Serga, I., Svinarenko, A., Ternovsky, E. Computational code in atomic and nuclear quantum optics: Advanced computing multiphoton resonance parameters for atoms in a strong laser field. J. Phys.: Conf. Ser. 2017, 905, 012004.

35. Glushkov, A; Khetselius, O; Svinarenko, A; Buyadzhi, V. Spectroscopy of autoionization states of heavy atoms and multiply charged ions. Odessa: 2015

36. Glushkov, A.V., Khetselius, O.Yu., Svinarenko, A.A., Buyadzhi, V.V. Methods of computational mathematics and mathematical physics. P.1. TES: Odessa, 2015.

37. Khetselius, O.Yu. Spectroscopy of cooperative electron-gamma-nuclear processes in heavy atoms: NEET effect. $J$. Phys.: Conf. Ser. 2012, 397, 012012.

38. Buyadzhi, V., Zaichko, P., Antoshkina, O., Kulakli, T., Prepelitsa, G., Ternovsky, V.B., Mansarliysky, V. Computing of radiation parameters for atoms and multicharged ions within relativistic energy approach: Advanced Code. J. Phys.: Conf. Ser. 2017, 905(1), 012003. Ignatenko, A.V. Probabilities of the radiative transitions between Stark sublevels in spectrum of atom in an DC electric field: New approach. Photoelectronics, 2007, 16, 71-74.

39. Glushkov, A.V.; Ambrosov, S.V.; Ignatenko, A.V. Non-hydrogenic atoms and Wannier-Mott excitons in a DC electric field: Photoionization, Stark effect, Resonances in ionization continuum and stochasticity. Photoelectronics, 2001, 10, 103-106.

40. Glushkov A., Ternovsky V., Buyadzhi V., Prepelitsa G., Geometry of a rela- 
tivistic quantum chaos: New approach to dynamics of quantum systems in electromagnetic field and uniformity and charm of a chaos. Proc. Intern. Geom. Center. 2014, 7(4), 60-71.

41. Glushkov A V, Ambrosov S V, Loboda A V, Chernyakova Yu G, Svinarenko A A and Khetselius O Yu QED calculation of the superheavy elements ions: energy levels, radiative corrections, and hfs for different nuclear models Nucl Phys A Nucl Hadr Phys 2004, 734, 21

42. Khetselius, O.Yu. Relativistic perturbation theory calculation of the hyperfine structure parameters for some heavyelement isotopes. Int. Journ.Quant Chem. 2009, 109, 3330-3335.

43. Khetselius, O. Hyperfine structure of radium. Photoelectronic. 2005, 14, 83-85.

44. Sukharev, D.E.; Khetselius, O.Yu.; Dubrovskaya, Yu.V. Sensing strong interaction effects in spectroscopy of hadronic atoms. Sensor Electr. and $\mathrm{Mi}$ crosyst. Techn. 2009, N3, 16-21.

45. Khetselius, O.Yu. Quantum structure of electroweak interaction in heavy finite Fermi-systems. Astroprint: Odessa, 2011.

46. Khetselius, O.Y.., Glushkov, A.V., Gurskaya, M.Y., Kuznetsova, A.A., Dubrovskaya, Yu.V., Serga, I.N., Vitavetskaya, L.A. Computational modelling parity nonconservation and electroweak interaction effects in heavy atomic systems within the nuclearrelativistic many-body perturbation theory. J. Phys.: Conf. Ser. 2017, 905(1), 012029.

47. Svinarenko, A. A., Glushkov, A. V., Khetselius, O.Yu., Ternovsky,V.B., Dubrovskaya, Yu., Kuznetsova, A., Buyadzhi, V. Theoretical spectroscopy of rare-earth elements: spectra and autoionization resonances. Rare Earth Element, Ed. J. Orjuela (InTech) 2017, pp 83-104

48. Glushkov, A.V., Khetselius, O.Yu., Svinarenko A.A., Buyadzhi, V.V., Ternovsky, V.B, Kuznetsova, A., Bashkarev, P Relativistic perturbation theory formalism to computing spectra and radiation characteristics: application to heavy element. Recent Studies in Perturbation Theory, ed. D. Uzunov (InTech) 2017, 131-150.

49. Danilov, V., Kruglyak, Y., Pechenaya, $\mathrm{V}$. Electron density-bond order matrix and the spin density in the restricted CI method. Theor. Chim Acta. 1969, 13(4), 288-296.

50. Glushkov A.V., Khetselius O.Yu., Loboda A.V., Ignatenko A., Svinarenko A., Korchevsky D., Lovett L., QED Approach to Modeling Spectra of the Multicharged Ions in a Plasma: Oscillator and Electron-ion Collision Strengths. AIP Conference Proceedings. 2008. 1058. 175-177

PACS 31.15.-p

\section{Buyadzhi V.V.}

\section{ELECTRON-COLLISIONAL SPECTROSCOPY OF ATOMS AND IONS: ADVANCED ENERGY APPROACH}

Summary. An advanced relativistic energy approach combined with a relativistic many-body perturbation theory with ab initio zeroth approximation is used to calculate the electroncollision excitation cross-sections for complex multielectron systems. The relativistic manybody perturbation theory is used alongside the gauge-invariant scheme to generate an optimal Dirac-Kohn-Sham- Debye-Hückel one-electron representation. The results of relativistic calculation (taking into account the exchange and correlation corrections) of the electron collision cross-sections of excitation for the neon-like ion of the krypton are presented and compared with alternative results calculation on the basis of the R-matrix method in the Breit-Pauli approximation, in the relativistic distorted wave approximation and R- matrix method in combination with Dirac-Fock approximation

Key words: spectroscopy of ions, relativistic energy approach, collision cross-sections. 


\section{РЕЛЯТИВИСТСКИЙ ЭНЕРГЕТИЧЕСКИЙ ПОДХОД И МНОГОЧАСТИЧНАЯ ТЕОРИЯ ВОЗМУЩЕНИЙ ДЛЯ ОПРЕДЕЛЕНИЯ СЕЧЕНИЙ ЭЛЕКТРОННО-СТОЛКНОВЕННОГО ВОЗБУЖДЕНИЯ ДЛЯ СЛОЖНЫХ МНОГОЭЛЕКТРОННЫХ ИОНОВ}

Резюме. Эффективный релятивистский энергетический подход в комбинации с многочастичной теорией возмущений с неэмпирическим нулевым приближением используется для расчета сечений электрон-столкновительного возбуждения для ряда сложных релятивистских многоэлектронных систем. Релятивистская многочастичная теория возмущений наряду с эффективной калибровочно-инвариантной схемой используется для генерации оптимального одноэлектронного представления Дирака-КонаШама-Дебая-Хюккеля. Приведены результаты релятивистского расчета (с учетом обменных и корреляционных поправок) сечений электрон-столкновительного возбуждения неоноподобного иона криптона и проведено сравнение с альтернативными результатами расчета на основе R-матричного метода в приближении Брейта-Паули, в релятивистском приближении искаженных волн и на основе R-матричного метода в сочетании с приближением Дирака-Фока.

Ключевые слова: спектроскопия ионов, энергетический подход, сечения столкновений

PACS 31.15.-p

Буяджи В.B.

\section{РЕЛЯТИВІСТСЬКИЙ ЕНЕРГЕТИЧНИЙ ПІДХІД І БАГАТОЧАСТИНКОВА ТЕОРІЯ ЗБУРЕНЬ ДЛЯ ВИЗНАЧЕННЯ ПЕРЕТИНІВ ЕЛЕКТРОННОГО ЗБУДЖЕННЯ ЗА РАХУНОК ЗІТКНЕНЬ ДЛЯ СКЛАДНИХ БАГАТОЕЛЕКТРОННІ ИОНОВ}

Резюме. Ефективний релятивістський енергетичний підхід в комбінації з багаточастинкової теорією збурень 3 неемпіричним нульовим наближенням використуються для розрахунку перетинів електронного збудження за рахунок зіткнень для ряду складних релятивістських багатоелектронних систем. Релятивістська багаточастинкова теорія збурень поряд з ефективною калібрувально-інваріантної схемою використуються для генерації оптимального одноелектронного уявлення Дірака-Кона-Шама-ДебаяХюккеля. Наведены результати релятивістського розрахунку (з урахуванням обмінних і кореляційних поправок) перетинів електрон-зіткнень збудження неоноподібного іона кріптону і проведено порівняння з альтернативними результатами розрахунків на основі R-матричного методу в наближенні Брейта-Паулі, в релятивістському наближенні спотворених хвиль і на основі R-матричного методу в поєднанні з наближенням ДіракаФока.

Ключові слова: спектроскопія іонів, енергетичний підхід, перерізи зіткнень. PACS 42.55.-f 